\title{
Effect of methyl jasmonate on physiological and biochemical quality changes of longkong fruit under low temperature storage
}

\author{
Karthikeyan Venkatachalam ${ }^{1 \star}$ and Mutita Meenune ${ }^{2}$ \\ 1 Department of Food Technology, Faculty of Science and Industrial Technology, Prince of Songkla University, Muang, Surat Thani 84100, \\ Thailand \\ 2 Department of Food Technology, Faculty of Agro-Industry, Prince of Songkla University, Hat-Yai, Songkhla 90112, Thailand
}

Received $1^{\text {st }}$ July 2014 - Accepted 21 November 2014

\begin{abstract}
Introduction. Longkong (Aglaia dookkoo Griff.) fruit is a non-climacteric tropical fruit and grows widely in the South-East Asia. It has a unique taste and nutritional properties that make it more valuable to export. However, longkong exhibits a shorter shelf life at ambient $\left(25^{\circ} \mathrm{C}\right.$ for $3-5$ days $)$ and low temperature $\left(13{ }^{\circ} \mathrm{C}\right.$ for 10 days $)$ storage. Therefore, there is an urgent need to extend its shelf life and marketability by using an inexpensive and proficient technique. Materials and methods. Methyl jasmonate (MeJA) treatments with different concentrations (10, 20 and $30 \mu \mathrm{Mol} \mathrm{L}{ }^{-1}$ ) were used to control physiological and biochemical quality changes of longkong fruit stored at $13{ }^{\circ} \mathrm{C}$ and $85 \%$ relative humidity. Fruit with no MeJA treatment served as control. The physiological and biochemical quality analyses were carried out at every four days of the interval. Results and discussion. Longkong pericarp chilling injury (CI) index and ion leakage severely increased in the control fruits as compared with MeJA treated fruit. The increased of pericarp phenylalanine ammonia lyase (PAL), polyphenol oxidase (PPO) and peroxidase (POD) activities were well controlled by MeJA treatments. Fruit polygalacturonase (PG), pectin methyl esterase (PME) and lipoxygenase (LOX) activities were significantly controlled in MeJA treated fruit. Fruit superoxide dismutase (SOD), catalase (CAT) and glutathione peroxidase (GPX) activities found higher level in the MeJA treated fruit. Conclusion. The different concentrations of MeJA treatment effectively reduced the severity of physiological and biochemical quality changes in longkong fruit under prolonged low temperature storage.
\end{abstract}

Keywords: Thailand / longkong / Aglaia dookkoo / cold storage / shelf life / methyl jasmonate / enzyme activity

Résumé - Effet du jasmonate de méthyle sur la qualité physiologique et biochimique des fruits du longkong à basse température. Introduction. Le longkong (Aglaia dookkoo Griff.) est un fruit tropical non-climactérique largement répandu en Asie du Sud-Est. Il a un goût unique et ses propriétés nutritionnelles en font un produit d'exportation recherché. Cependant, le longkong présente une durée de vie très courte à température ambiante $\left(3-5\right.$ jours à $\left.25^{\circ} \mathrm{C}\right)$ et un peu prolongée à basse température $\left(10\right.$ jours à $\left.13{ }^{\circ} \mathrm{C}\right)$. Pour développer cette espèce, il est crucial d'étendre sa durée de vie et sa valeur marchande. Nous avons proposé d'utiliser une technique peu coûteuse et efficace sur d'autres espèces. Matériel et méthodes. Des traitements au jasmonate de méthyle (MeJA) ont été appliqués aux concentrations de 10,20 et $30 \mu \mathrm{mol} \mathrm{L}{ }^{-1}$ dans le but de contrôler la qualité des fruits du longkong stockés à $13{ }^{\circ} \mathrm{C}$ et $85 \%$ d'humidité relative. Les fruits sans traitement MeJA ont servi de témoin. L'analyse des critères de qualité, biochimiques et physiologiques, a été réalisée tout au long du stockage à quatre jours d'intervalle. Résultats et discussion. Les blessures sur le péricarpe du longkong (CI) et l'indice de fuite d'ions, toutes deux dues au froid, ont fortement augmenté sur les fruits du témoin par rapport à ceux traités au MeJA. L'augmentation des activités enzymatiques de la phénylalanine ammonialyase (PAL), de la polyphénol-oxydase (PPO) et de la peroxydase (POD) du péricarpe des fruits a été bien contrôlée par les traitements au MeJa. Les activités polygalacturonase (PG), pectine méthyle estérase (PME) et lipoxygénase (LOX) du fruit ont été largement contrôlées par les traitements au MeJA. La superoxyde-dismutase (SOD), la catalase (CAT) et la glutathionpéroxydase (GPX) du fruit ont eu une activité plus élevée dans les fruits traités au MeJA. Conclusion. Les différentes concentrations de MeJA ont toutes été efficaces pour réduire la gravité des altérations tant physiologiques que biochimiques au cours du stockage prolongé du longkong à basse température.

Mots clés : Thaïlande / longkong / Aglaia dookkoo / stockage au froid / durée de vie / jasmonate de méthyle / activité enzymatique

\footnotetext{
* Corresponding author: karthikeyan.v@psu.ac.th
} 


\section{Introduction}

Longkong fruit (Aglaia dookkoo Griff., syn. Lansium domesticum) is one of the important horticultural produce in Thailand, also known as langsat. Longkong is a nonclimacteric and tropical fruit. It contains a high level of antioxidant activities, nutritional and medicinal properties. However, longkong is highly perishable at an ambient temperature due to physiochemical changes such as pericarp browning, fruit firmness and the off-flavour formation and thus, limit the fruit shelf life to $3-5$ days [1]. Low temperature storage is extensively used to prolong the shelf life and maintain the quality of fruit and vegetables by delaying their senescence and deteriorations process. Longkong fruit stored below an ambient temperature has increased the shelf life by several weeks. Tropical and subtropical fruit stored at a very low temperature could cause the severe chilling injury symptoms [2].

Chilling injury might be the consequence of oxidative stress caused by reactive oxygen species (ROS) during the prolonged storage [3]. Longkong fruit stored at a low temperature between $12{ }^{\circ} \mathrm{C}$ and $15{ }^{\circ} \mathrm{C}$ had a chilling injury disorder such as pitting, scalding on fruit pericarp and loss of firmness. Phenylalanine ammonia lyase (PAL), Polyphenol oxidase (PPO) and peroxidase (POD) are the predominant enzymes that inducing pericarp browning in longkong [4]. Polygalacturonase (PG) and pectin methyl esterase (PME) are the main enzymes that contribute to changes in fruit firmness [5]. Additionally, lipoxygenase (LOX) is considered as one of the major enzymes responsible for membrane deterioration in a number of plant tissues under various stress conditions [6]. Methyl jasmonate (MeJA) is a cyclopentanone compound, and it considered as an endogenous plant regulator that plays a vital role on stress response, plant growth and development $[7,8]$.

Recently, MeJA has been used widely as a potential postharvest application for the alleviation of chilling injury in many horticultural crops and keep their quality $[9,10]$. Several reports have elucidated that, MeJA eases the chilling injury by increasing the expression of a set of defense genes and enhances the antioxidant capacity in crops. Superoxide dismutase (SOD), catalase (CAT) and glutathione peroxidase (GPX) are the primary antioxidant enzymes that usually observed a high level of activity in MeJA treated plant produces under low temperature storage $[5,11]$. Until now, there are only a few limited reports available on controlling longkong chilling injury symptoms. There is no information on using the exogenous MeJA treatment to control the enzyme activities, which induced the physiological and biochemical quality changes and chilling injury symptoms in longkong under low temperature storage. Therefore, our objective was to examine the effect of MeJA with different concentrations on physiological and biochemical quality changes of longkong fruit under prolonged low temperature storage.

\section{Material and methods}

\subsection{Plant material}

The fully matured longkong fruit (91 days after anthesis) were purchased from a contact garden in southern Thailand.
The harvested fruit were taken into the laboratory within $2 \mathrm{~h}$ at an ambient temperature. Received fruit were carefully removed from the racemes without any apparent damages and they were washed in distilled water to remove any dirt and pests. The fruit pericarp surface was then dried using an electric fan (approximately $30 \mathrm{~min}$ ) at an ambient temperature. After that, the fruit proceeded to different concentrations of MeJA treatment and storage.

\subsection{MeJA treatment and storage}

Longkong fruit were separated randomly into four groups. The first group (MeJA not treated) served as a control. The second, the third and the fourth groups were treated with 10, 20 and $30 \mu \mathrm{Mol} \mathrm{L}^{-1} \mathrm{MeJA}$, respectively. All groups were kept in an air-sealed container and fumigated with MeJA (except the control fruit) for $24 \mathrm{~h}$ at an ambient temperature and then, ventilated for at least $2 \mathrm{~h}$. After the treatments, 15 longkong fruits were placed on a perforated polypropylene punnet box for each replication. Then, the fruit were stored at $13{ }^{\circ} \mathrm{C}$ and $85 \%$ relative humidity until the storage ended. Fruit shelf life periods were terminated when the visible mould growth and/or more than $75 \%$ of chilling injury symptoms appeared on the fruit pericarp. Fruit were measured on the following quality determinations at every four days of the interval.

\subsection{Physical quality evaluations}

Symptoms of chilling injury (CI), including pitting and brown scalding on the fruit pericarp were visually assessed. The severity of the symptoms was evaluated after $10 \mathrm{~h}$ of fruit transfer from $13{ }^{\circ} \mathrm{C}$ to $25{ }^{\circ} \mathrm{C}$ following the method of Jin et al. [12]. The results were expressed in percentage (\%). Pericarp electrolyte leakage was calculated by the method of Saltveit [13]. The electrolytic leakage values were expressed as the percentage ratio of the initial over total conductivity. Fruit firmness was measured on four sides of 15 peeled fruits from each replication using a TA-XT2i (Stable Micro System, UK) texture analyzer with a $2 \mathrm{~mm}$ diameter cylinder probe with the penetrometric methods. The results were expressed in Force $(\mathrm{N})$.

\subsection{Enzyme activity analysis}

The browning-related enzyme (PAL, PPO and POD) activities were analyzed in longkong fruit pericarp. At the same time, fruit flesh was used to analyze the textural (PG, PME and LOX) and antioxidant (SOD, CAT and GPX) enzyme activities.

For PAL activity, pericarp tissues $(2 \mathrm{~g})$ from 20 fruits were homogenized at $4{ }^{\circ} \mathrm{C}$ in $20 \mathrm{~mL}$ of $0.1 \mathrm{M}$ sodium borate buffer (pH 8.0) solution, which contained 0.2 g polyvinyl pyrrolidone (PVP), $5 \mathrm{mM}$ mercaptoethanol and $2 \mathrm{mM}$ ethylenediamine tetra acetic acid (EDTA). The homogenized sample was filtered through cheesecloth and the filtrate was centrifuged at $19,000 \mathrm{~g}$ for $20 \mathrm{~min}$ at $4{ }^{\circ} \mathrm{C}$. The supernatant was collected 
for analyzing PAL activity utilizing the method of Jiang and Joyce [14].

For PPO activity, pericarp tissues $(2 \mathrm{~g})$ from 20 fruits were homogenized at $4{ }^{\circ} \mathrm{C}$ in $40 \mathrm{~mL}$ of $0.2 \mathrm{M}$ sodium phosphate buffer ( $\mathrm{pH}$ 6.4) solution. The homogenized sample was filtered through cheesecloth and the filtrate centrifuged at $12,000 \mathrm{~g}$ for $30 \mathrm{~min}$ at $4{ }^{\circ} \mathrm{C}$. The supernatant of crude extract was collected for analyzing PPO activity according to the method of Tian, $\mathrm{Xu}$ [15].

For POD activity, pericarp tissues $(2 \mathrm{~g})$ from 20 fruits were homogenized at $4{ }^{\circ} \mathrm{C}$ in $20 \mathrm{~mL}$ of $0.05 \mathrm{M}$ phosphate buffer $(\mathrm{pH} 7)$ solution and $0.2 \mathrm{~g}$ of insoluble polyvinylpyrrolidone (PVP). The homogenate was filtered through cheesecloth and the filtrate centrifuged at $19,000 \mathrm{~g}$ for $20 \mathrm{~min}$ at $4{ }^{\circ} \mathrm{C}$. The supernatant of crude extract was collected for analyzing POD activity according to the method of Venkatachalam and Meenune [4].

For PG activity, fruit flesh $(10 \mathrm{~g})$ was homogenized at $4{ }^{\circ} \mathrm{C}$ in $10 \mathrm{~mL}$ of $0.2 \mathrm{Mol} \mathrm{L}^{-1}$ acetic acid buffer (pH 6.0) solution. The homogenate was filtered through cheesecloth and the filtrate centrifuged at $11,000 \mathrm{~g}$ for $20 \mathrm{~min}$ at $4{ }^{\circ} \mathrm{C}$. The supernatant of crude enzyme extract was collected for analyzing PG activity according to the method of Qiuping and Wenshui [16].

For PME activity, fruit flesh $(10 \mathrm{~g})$ was homogenized at $4{ }^{\circ} \mathrm{C}$ in $20 \mathrm{~mL} 8.8 \%(\mathrm{w} / \mathrm{v}) \mathrm{NaCl}$ solution and $0.5 \mathrm{~g}$ polyvinylpyrrolidone. The homogenate was filtered through cheesecloth and the filtrate centrifuged at $10,000 \mathrm{~g}$ for $30 \mathrm{~min}$ at $4{ }^{\circ} \mathrm{C}$. The supernatant of crude extract was collected, adjusted the $\mathrm{pH}$ to 7.5 and used for analyzing PME activity according to the method of Hagerman and Austin [17].

For LOX activity, fruit flesh $(10 \mathrm{~g})$ was homogenized at $4{ }^{\circ} \mathrm{C}$ in $10 \mathrm{~mL}$ EDTA solution The homogenate was filtered through cheesecloth and the filtrate centrifuged at $10,000 \mathrm{~g}$ for $30 \mathrm{~min}$ at $4{ }^{\circ} \mathrm{C}$. The supernatant of crude extract was collected and analyzed for LOX activity according to the method of Sharma, Sharma [6].

For SOD activity, fruit flesh $(10 \mathrm{~g})$ was homogenized at $4{ }^{\circ} \mathrm{C}$ in $25 \mathrm{~mL}$ of buffer solution $(100 \mathrm{mM}$ sodium phosphate buffer (pH 6.4)) and 0.5 g PVP. The homogenate was filtered through cheesecloth and the filtrate centrifuged at $19,000 \mathrm{~g}$ for $30 \mathrm{~min}$ at $4{ }^{\circ} \mathrm{C}$. The supernatant was collected and analyzed for SOD activity according to the method of Cao et al. [5].

For CAT activity, fruit flesh $(10 \mathrm{~g})$ was homogenized at $4{ }^{\circ} \mathrm{C}$ in $25 \mathrm{~mL}$ of buffer solution $(50 \mathrm{mM}$ sodium phosphate buffer ( $\mathrm{pH}$ 7.0)) and $0.5 \mathrm{~g}$ PVP. The homogenate was filtered through cheesecloth and the filtrate centrifuged at $19,000 \mathrm{~g}$ for $30 \mathrm{~min}$ at $4{ }^{\circ} \mathrm{C}$. The supernatant of crude enzyme extract was collected and analyzed for CAT activity according to the method of Cao et al. [5].

For GPX activity, fruit flesh $(10 \mathrm{~g})$ was homogenized at $4{ }^{\circ} \mathrm{C}$ in $25 \mathrm{~mL}$ of buffer solution $(100 \mathrm{mM}$ Tris $\mathrm{HCl}$ Buffer (pH 7.5), $1 \mathrm{mM}$ EDTA, $0.1 \%$ PVP and $7 \mathrm{mM}$ $\beta$-mercaptoethanol). The homogenate was filtered through cheesecloth and the filtrate centrifuged at $12,000 \mathrm{~g}$ for $15 \mathrm{~min}$ at $4{ }^{\circ} \mathrm{C}$. The supernatant of crude enzyme extract was collected and analyzed for GPX activity according to the method of Putter [18].

Protein content was determined from the crude enzyme extracts in accord with the method of Bradford [19] and using bovine serum albumin as a standard. The specific activity of all the enzyme extracts was shown as a unit per mg protein.

\subsection{Statistical analysis}

The treatment and determination of samples were done in triplicate. The data were analyzed by one-way analysis of variance (ANOVA) with the Statistical Package for Social Science (SPSS for windows, SPSS Inc., Chicago, IL, USA). The significance of the difference among treatments was measured using Duncan's new multiple range tests (DMRT), with a level of significance of 0.05 .

\section{Results and discussion}

\subsection{Physical quality analysis}

Longkong fruit exhibited severe CI symptoms in the control fruit samples after storage for four days. Conversely, MeJA treated fruits were observed to have the least incidence of CI during prolonged storage $(P<0.05)$. As shown in figure $1 A$, fruit pericarp pitting and brown scalding was less than $45 \%$ in MeJA treated fruits whereas the CI symptoms in the control was reached above $75 \%$ following storage. The higher concentration of MeJA treatment maintained the lesser level (below $30 \%$ ) of CI symptoms than the lower concentration of MeJA treated fruits. MeJA treatment might induce the accumulation of heat shock protein and accelerate the antioxidant enzymes (SOD, CAT and GPX) in fruit to increase the tolerability from chilling injury and consequently, reach a lower CI index. Pericarp ion leakage is identified as an indicator of membrane degradation. The control fruits had a high level of electrolytic leakage than the MeJA treated fruits (figure $1 B$ ). This indicates that MeJA treatment maintained the membrane integrity of fruit pericarp and thus reduced the ion leakage during storage. The control fruit ion leakage was achieved above $40 \%$ whereas, the MeJA treated fruits kept the pericarp ion leakage below 30\% during storage. According to Aghdam and Bodbodak [20] the exogenous treatment of MeJA controlled the membrane integrity loss by suppressing the activity of membrane degrading enzymes (LOX). The higher concentration of MeJA ( 20 and $30 \mathrm{mMol} \mathrm{L}^{-1}$ ) reduced the increase of ion leakage $(P \geqslant 0.05)$ than the lower concentration during storage. Fruit firmness changes during storage are shown in figure $1 C$. During the prolonged storage, fruit firmness tended to decrease continuously in all the treatments $(P<0.05)$. The control fruits experienced a decrease in firmness levels than the MeJA treatments. This could be due to chilling induced activities of fruit PG, PME and LOX during storage as seen in figure $3 A-3 C$. The higher concentration of MeJA treatment retained more fruit firmness than a low concentration. The fruit firmness reduced gradually while long standings of cold storage are in parallel with pectin harmonious modification resulting from the enzymatic catalysis of metabolism and nonenzymatic cation change [9]. 

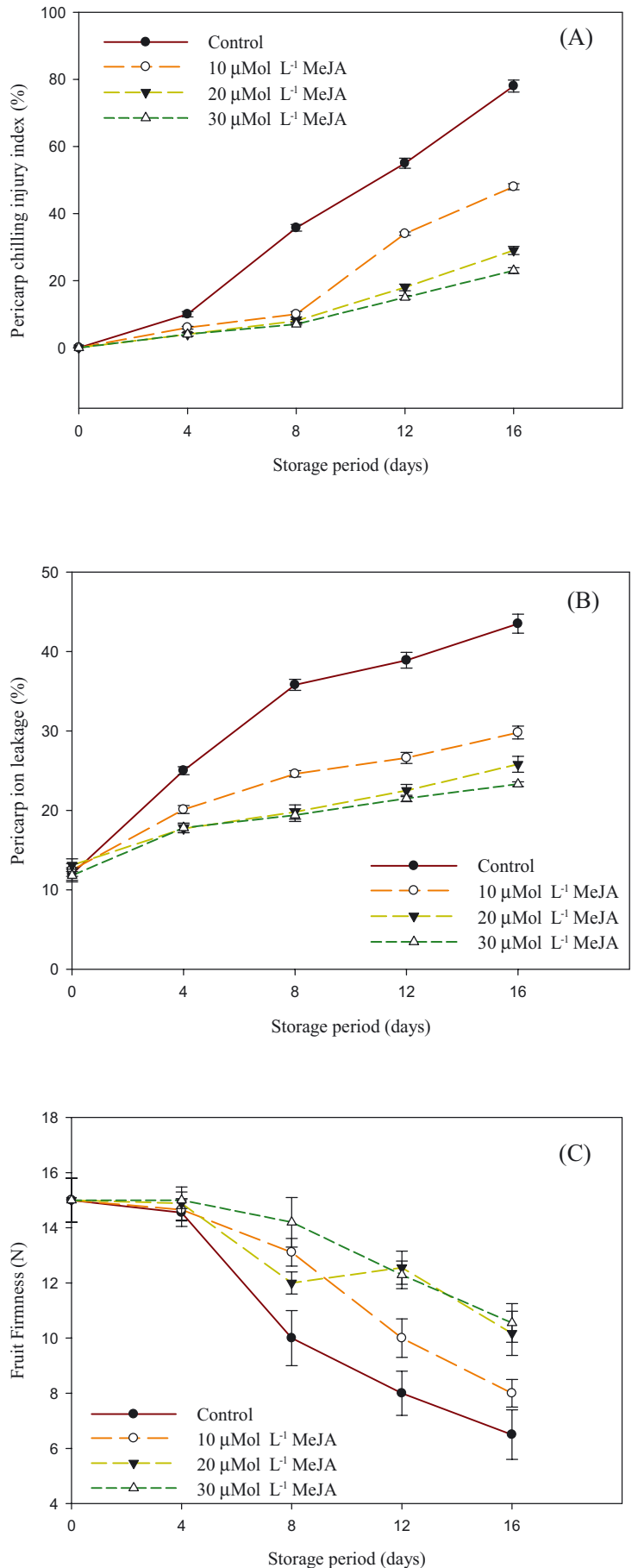

Figure 1. Effect of exogenous MeJA treatment on changes of longkong fruit physical qualities under low temperature storage. Vertical bars represent standard deviation.

\subsection{Pericarp browning enzyme activities}

The higher level of longkong fruit pericarp PAL activity was observed in the control than in the MeJA treated fruits during storage $(P<0.05)$ (figure $2 A)$. MeJA treated fruits sustained the suppression of PAL activity during storage. The higher concentration of MeJA treated fruits had a severe control on PAL activity as compared to a lower concentration.
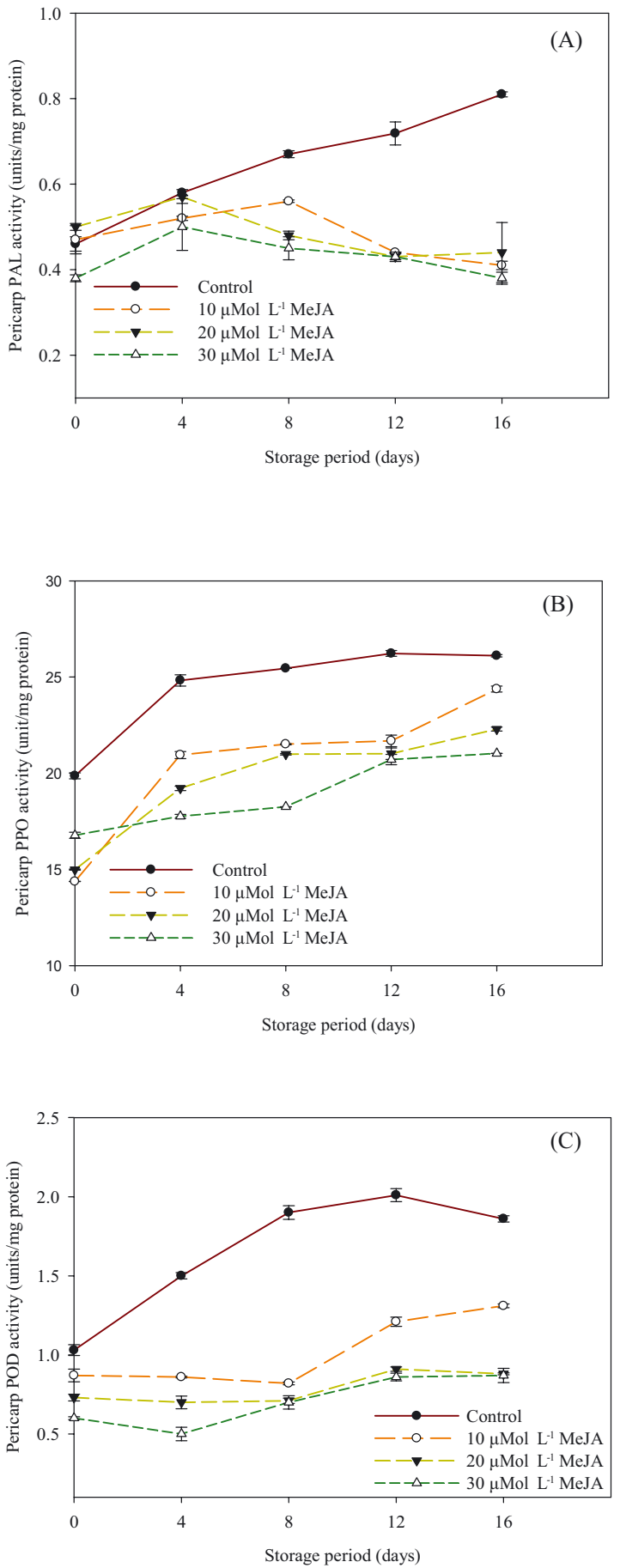

Figure 2. Effect of exogenous MeJA treatment on changes of longkong fruit browning related enzyme activities under low temperature storage. PAL: Phenylalanine ammonia lyase, PPO: polyphenol oxidase, POD: peroxidase. Vertical bars represent standard deviation.

Cao et al. [7] reported; PAL is a precursor for the biosynthesis of lignin,which generates the chilling injury in many horticultural produces. A decreased incidence of chilling injury in MeJA treated fruits could be the controlled activity of PAL. The increased activity of PPO and POD was observed in the fruit pericarp during storage $(P<0.05)$. Although the increased PPO and POD activities were seen in higher levels 
in the control than MeJA treated fruits (figure $2 B-2 C$ ) $\mathrm{PPO}$ and POD have been shown to be responsible for produce pericarp browning in longkong by oxidized the pericarp phenolics [4]. The different concentration of MeJA treatment had a significant control in longkong fruit pericarp PAL, PPO and POD activities during storage $(P<0.05)$. The PAL, PPO and POD enzyme activities were adequately controlled by the higher concentration of MeJA treated fruits as compared to low concentration and control fruits. The interaction between MeJA treatments and storage period significantly influenced the longkong fruit pericarp browning related enzyme activities $(P<0.05)$. The inhibitory effect of MeJA treatment on PAL, PPO and POD activity has been demonstrated in many fruit $[7,9]$. The increased activity of PAL, PPO and POD in control fruits could be involved in protecting this effect against the microbial attack during at a low temperature with high $\mathrm{RH}$ storage. Longkong fruit stored at a low temperature with high relative humidity conditions could increase the visible mould growth on the fruit pericarp surface [1]. MeJA itself acted as an antimicrobial activity and it could be a reason that the lower activities of PPO and POD were observed in fruit pericarp as compared to the control. However, MeJA effect on the browning related enzyme activities is varied with the plant species.

\subsection{Fruit textural enzyme activities}

PG and PME are the essential enzymes that relate to reducing various fruit firmness while ripening and storage [21]. Fruit PG and PME activities were increased in all the treatments throughout storage (figure $3 A-3 B$ ). During the storage, the control fruits had a high level of PG and PME activities than the MeJA treated fruit. The MeJA treated fruit suppressed the intensity of the increase of PG and PME activities during storage. MeJA treated fruit with higher concentration effectively suppressed the increased activities of PG and PME. The interaction between MeJA treatments and storage period significantly affected the textural enzymes of longkong fruit $(P<0.05)$. Ziosi et al. [22] reported that MeJA treated peach fruit decreased in PG activity during prolonged cold storage. Meng et al. [9] reported that MeJA treatment reduced the PME activity by inhibiting the de-esterification of protein. Jhalegar et al. [23] reported that the polyamines can delay the senescence and keep the firmness of fruit under the different stress conditions. Zhang et al. [8] reported that MeJA treated cherry tomato fruit increased in the biosynthesis of polyamines under prolonged low temperature stress. Similarly, MeJA treatment also suppressed the increased activity of LOX in longkong during prolonged storage (figure $3 C$ ). The control fruit LOX activity was steadily increased during storage whereas different concentrations of MeJA treatment significantly controlled LOX activity. The increased concentration of MeJA provided a better result on controlling LOX activity than lower concentration. LOX is the participant in the stress-induced membrane alterations and lipid degradation in plants [6]. Mao et al. [24] reported that the development of chilling injury in cucumber fruit was accompanied by the increased activity of LOX. Cao et al. [5] observed that MeJA treated loquat fruits decreased in LOX activity during the chilling storage.
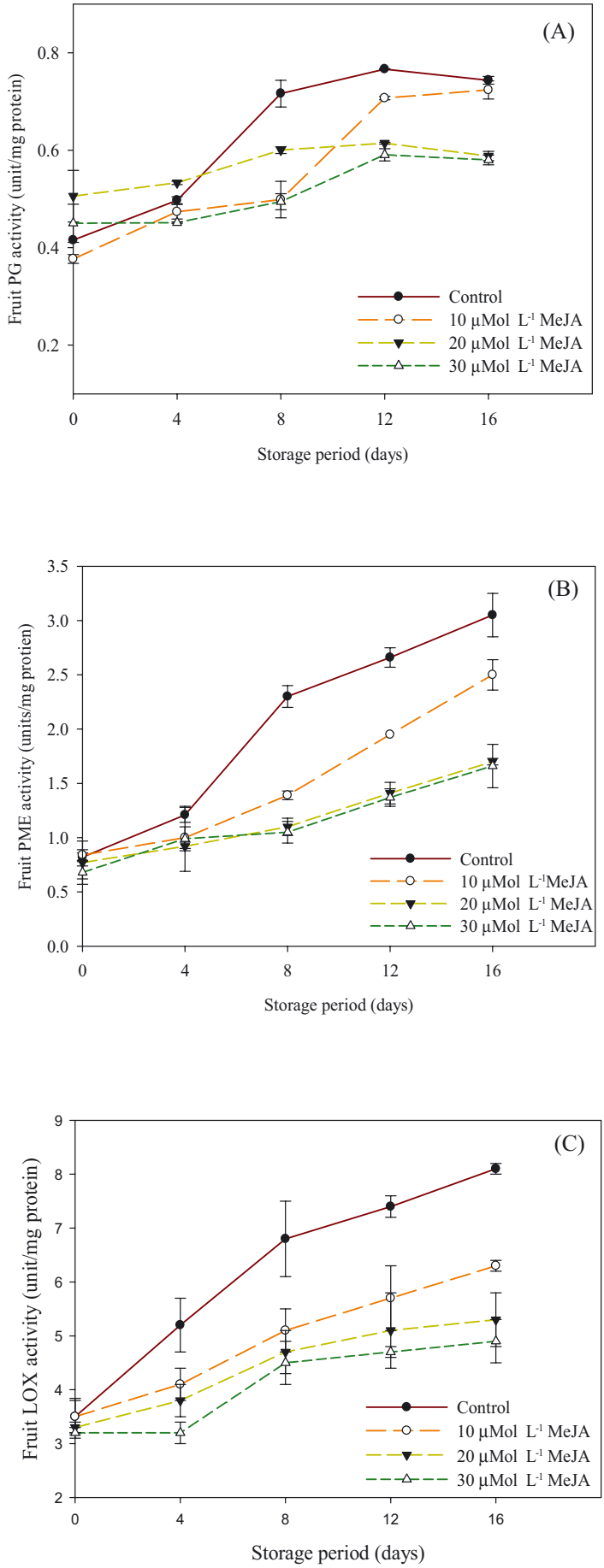

Figure 3. Effect of exogenous MeJA treatment on changes of longkong fruit textural enzyme activities under low temperature storage. PG: polygalacturonase, PME: pectin methyl esterase, LOX: lipoxygenase. Vertical bars represent standard deviation.

\subsection{Fruit antioxidant enzyme activities}

SOD activity in the control and MeJA treated longkong fruits were increased with the longer storage period (figure 4A). The MeJA treated fruits had retained more SOD activity than the control fruits $(P<0.05)$. CAT and GPX activities increased at the initial period of storage and 

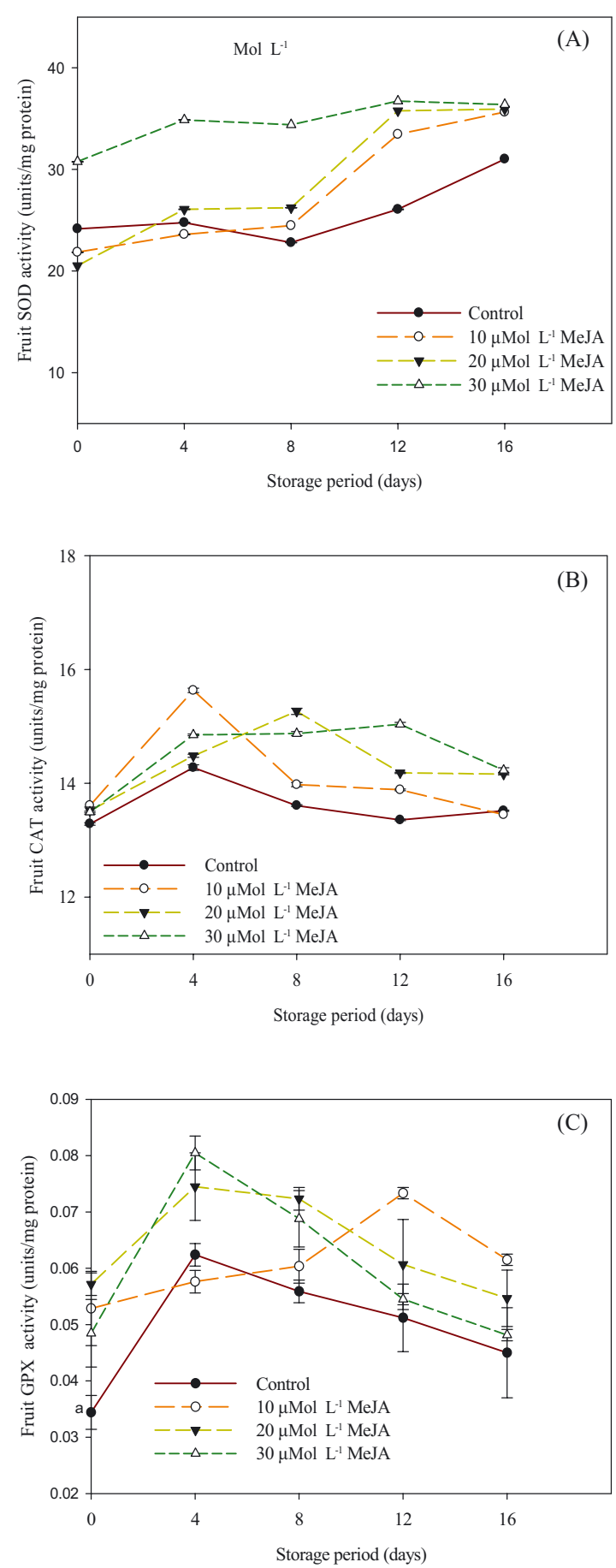

Figure 4. Effect of exogenous MeJA treatment on changes of longkong fruit antioxidant enzyme activities under low temperature storage. SOD: superoxide dismutase, CAT: catalase, GPX: glutathione peroxidase. Vertical bars represent standard deviation

throughout the storage slightly decreased (figure 4B-4C) $(P<$ $0.05)$. The different concentration of MeJA significantly retained the antioxidant enzyme activities in longkong fruit throughout the storage period $(P<0.05)$. Conversely, the control fruits obtained a low level of antioxidant enzyme activities during storage. The higher concentration of MeJA treated fruits had the higher activity of SOD and CAT as compared with the lower concentration and the control fruits during storage. Whereas, the GPX activity was initially found to have a higher level in longkong fruit treated with an increased concentration of MeJA and after that, at the end of storage, the activity was observed higher level in MeJA treated fruits in low concentration. The interaction between MeJA treatments and storage time was significantly affected the SOD, CAT and GPX activities $(P<0.05)$. Several findings reported that the increased reactive oxygen species by oxidative stress during low temperature storage might be contributed to chilling injury due to damaging the cell membrane [3,24]. Fruit under chilling stress, the MeJA effectively involved and increased the concurrent action of SOD, CAT and GPX activity and subsequently had counteract the chilling injury onset. MeJA is interacted in the signaling pathway mediating induced defense responses in chilling-stressed plants, and the onset of the tolerance has frequently been correlated with the accumulation of antioxidant enzymes and compounds [5].

\section{Conclusion}

MeJA treated longkong fruits effectively minimized the physiological and biochemical quality changes induced by chilling injury incidence during prolonged low temperature storage. MeJA treatments controlled the browning (PAL, PPO and POD) and textural related (PG, PME and LOX) enzyme activities and thus decreased the incidence of pericarp browning and loss of fruit firmness. Antioxidant enzyme activities were observed at a higher level in MeJA treated fruits than in the control during storage. The higher concentration of MeJA treated longkong fruits were better controlled of chilling injury symptoms (CI index and ion leakage) than at lower concentrations during prolonged storage period.

Acknowledgements. The authors are highly appreciative to Prince of Songkla University for general financial support through the graduate funding.

\section{References}

[1] Venkatachalam K., Meenune M., Physical and chemical quality changes of longkong (Aglaia dookkoo Griff.) During passive modified atmospheric storage, Inter. Food Res. J. 19 (2012) 795-800.

[2] Ketsa S., Paull R.E., Meliacease, in: Janick J., Paull R.E. (Eds.), The encyclopedia of fruits and nuts, CAB International, United Kingdom, 2008.

[3] Fung R.W.M., Wang C.Y., Smith D.L., Gross K.C., Tian M., MeSA and MeJA increase steady-state transcript levels of alternative oxidase and resistance against chilling injury in sweet peppers (Capsicum annuum L.), Plant Sci. 166 (2004) 711-719.

[4] Venkatachalam K., Meenune M., Changes in physiochemical quality and browning related enzyme activity of longkong fruit during four different weeks of on-tree maturation, Food Chem. 131 (2012) 1437-1442.

[5] Cao S., Zheng Y., Wang K., Jin P., Rui H., Methyl jasmonate reduces chilling injury and enhances antioxidant enzyme activity in postharvest loquat fruit, Food Chem. 115 (2009) 1458-1463. 
[6] Sharma S., Sharma R.R., Pal K.R., Jhalegar J., Singh J., Srivatsav M., Dhiman R.M., Ethylene absorbents influence fruit firmness and activity of enzymes involved in fruit softening of Japanese plum (Prunus slicina Lindell) cv. Santa Rosa, Fruits. 67 (2012) 257-266.

[7] Cao S., Zheng Y., Wang K., Rui H., Tang S., Effect of methyl jasmonate on cell wall modification of loquat fruit in relation to chilling injury after harvest, Food Chem. 118 (2010) 641-647.

[8] Zhang X., Sheng J., Li F., Meng D., Shen L., Methyl jasmonate alters arginine catabolism and improves postharvest chilling tolerance in cherry tomato fruit, Postharvest Biol. Technol. 64 (2012) 160-167.

[9] Meng X., Han J., Wang Q., Tian S., Changes in physiology and quality of peach fruits treated by methyl jasmonate under low temperature stress, Food Chem. 114 (2009) 1028-1035.

[10] Li D.-M., Guo Y.-K., Li Q., Zhang J., Wang X.-J., Bai J.-G., The pretreatment of cucumber with methyl jasmonate regulates antioxidant enzyme activities and protects chloroplast and mitochondrial ultrastructure in chilling-stressed leaves, Sci. Hort. 143 (2012) 135-143.

[11] Cao S., Cai Y., Yang Z., Zheng Y., MeJA induces chilling tolerance in loquat fruit by regulating proline and $\gamma$-aminobutyric acid contents, Food Chem. 133 (2012) 1466-1470.

[12] Jin P., Zheng Y., Tang S., Rui H., Wang C.Y., A combination of hot air and methyl jasmonate vapor treatment alleviates chilling injury of peach fruit, Postharvest Biol. Technol. 52 (2009) 24-29.

[13] Saltveit M.E., The rate of ion leakage from chilling-sensitive tissue does not immediately increase upon exposure to chilling temperatures, Postharvest Biol. Technol. 26 (2002) 295-304.

[14] Jiang Y., Joyce D., ABA effects on ethylene production, PAL activity, anthocyanin and phenolic contents of strawberry fruit, Plant Growth Regul. 39 (2003) 171-174.

[15] Tian S., Xu Y., Jiang A., Gong Q., Physiological and quality responses of longan fruit to high $\mathrm{O}_{2}$ or high $\mathrm{CO}_{2}$ atmospheres in storage, Postharvest Biol. Technol. 24 (2002) 335-340.

[16] Qiuping Z., Wenshui X., Effect of 1-methylcyclopropene and/or chitosan coating treatments on storage life and quality maintenance of Indian jujube fruit, LWT - Food Sci. Technol. 40 (2007) 404-411.

[17] Hagerman A.E., Austin P.J., Continuous spectrophotometric assay for plant pectin methyl esterase, J. Agric. Food Chem. 34 (1986) 440-444.

[18] Putter J., Peroxidase, in: Bergmeye H.U. (Ed.), Methods of enzymatic analysis, Verlag Chemie, Weinhan, 1974.

[19] Bradford M.M., A rapid and sensitive method for the quantitation of microgram quantities of protein utilizing the principle of protein-dye binding, Anal. Biochem. 72 (1976) 248-254.

[20] Aghdam M.S., Bodbodak S., Physiological and biochemical mechanisms regulating chilling tolerance in fruits and vegetables under postharvest salicylates and jasmonates treatments, Sci. Hort. 156 (2013) 73-85.

[21] Sayyari M., Babalar M., Kalantari S., Martínez-Romero D., Guillén F., Serrano M., Valero D., Vapour treatments with methyl salicylate or methyl jasmonate alleviated chilling injury and enhanced antioxidant potential during postharvest storage of pomegranates, Food Chem. 124 (2011) 964-970.

[22] Ziosi V., Bonghi C., Bregoli A.M., Trainotti L., Biondi S., Sutthiwal S., Kondo S., Costa G., Torrigiani P., Jasmonateinduced transcriptional changes suggest a negative interference with the ripening syndrome in peach fruit, J. Exp. Bot. 59 (2008) 563-573.

[23] Jhalegar M.J., Sharma R.R., Pal R.K., Rana V., Effect of postharvest treatments with polyamines on physiological and biochemical attributes of kiwifruit (Actinidia deliciosa) cv. Allison, Fruits. 67 (2012) 13-22.

[24] Mao L., Pang H., Wang G., Zhu C., Pospholipase D and lipoxygenase activity of cucumber fruit in response to chilling stress, Postharvest Biol. Technol. 44 (2007) 42-47.

Cite this article as: Karthikeyan Venkatachalam, Mutita Meenune. Effect of methyl jasmonate on physiological and biochemical quality changes of longkong fruit under low temperature storage. Fruits 70 (2015) 69-75. 